\title{
I $^{-}$Ions as Obstacles to Dislocation Motion in NaCl:I ${ }^{-}$Single Crystals
}

\author{
Yohichi Kohzuki ${ }^{*}$, Tomiyasu Ohgaku² \\ ${ }^{1}$ Department of Mechanical Engineering, Saitama Institute of Technology, Fukaya, Japan \\ ${ }^{2}$ Graduate School of Natural Science and Technology, Kanazawa University, Kanazawa, Japan \\ Email: "kohzuki@sit.ac.jp
}

Received 15 March 2016; accepted 22 April 2016; published 25 April 2016

Copyright (C) 2016 by authors and Scientific Research Publishing Inc.

This work is licensed under the Creative Commons Attribution International License (CC BY). http://creativecommons.org/licenses/by/4.0/

cC) (i) Open Access

\section{Abstract}

Strain-rate cycling tests associated with the ultrasonic oscillation were conducted for the purpose of investigation on the interaction between dislocation and $\mathrm{I}^{-}$ions during plastic deformation of $\mathrm{NaCl}: \mathrm{I}^{-}(0.5 \mathrm{~mol} \%$ in the melt) at $77 \mathrm{~K}$ to room temperature. The relative curves of stress decrement $(\Delta \tau)$ due to the oscillation and strain-rate sensitivity $(\lambda=\partial \tau / \partial \ln \dot{\varepsilon})$ have stair-like shape for $\mathrm{NaCl}$ single crystals doped with $\mathrm{I}^{-}$at low temperatures. There are two bending points and two plateau regions. $\lambda$ decreases with $\Delta \tau$ between the two bending points. $\tau_{p}$ at $\Delta \tau$ of first bending point and $\lambda_{p}$ between $\lambda$ at first plateau place and at second one depend on the dopant ions as weak obstacles to dislocation motion. Not only temperature dependence of $\tau_{p}$ and $\lambda_{p}$ but also $\tau_{p}$ versus $V$ (activation volume) reflects the interaction between dislocation and $I^{-}$ions. On the basis of the data (i.e. $\tau_{p}$ and $\lambda_{p}$ ) analyzed in terms of the relative curves of $\Delta \tau$ and $\lambda$, the activation energy, $G_{0}$, for the overcoming of dislocation from the dopant ion is found to be 0.47 and $0.53 \mathrm{eV}$ for $\mathrm{NaCl}: \mathrm{Br}^{-}$ and $\mathrm{NaCl}: \mathrm{I}^{-}$, respectively. This result that $G_{0}$ for $\mathrm{NaCl}: \mathrm{I}^{-}$is somewhat larger than for $\mathrm{NaCl}: \mathrm{Br}^{-}$leads to the phenomenon that $\mathrm{I}^{-}$ions are slightly stronger than $\mathrm{Br}^{-}$ones as weak obstacles to dislocation motion because of the difference between isotropic strains around $\mathrm{I}^{-}$ion and around $\mathrm{Br}^{-}$in $\mathrm{NaCl}$ single crystal. Furthermore, the values of $\tau_{p 0}$ and $T_{\mathrm{c}}$ are also obtained for the two kinds of specimens. $\tau_{p 0}$ and $T_{\mathrm{c}}$ are the value of $\tau_{p}$ at absolute zero and critical temperature at which $\tau_{p}$ becomes zero.

\section{Keywords}

Dislocation, Ultrasonic Oscillatory Stress, Activation Energy

${ }^{*}$ Corresponding author. 


\section{Introduction}

Strength of materials is influenced by the interaction between dislocation and impurities, which has been widely investigated by the yield stress measurements [1]-[4], the direct observations of dislocation [5] [6], the internal friction measurements [7]-[9] and so on. However, it is difficult to investigate it in bulk during plastic deformation by the all methods. This is because yield stress depends on dislocation velocity, dislocation density and multiplication of dislocations [10]. As for direct observation, electron microscopy provides the information on the interaction between a dislocation and obstacles for a thin specimen but not for bulk. Internal friction measurement cannot provide the information on the motion of the dislocation which moves by overcoming the forest dislocations and the weak obstacles such as impurities during plastic deformation because the measurement concerns the motion of the dislocation which breaks away from the weak obstacles between two forest dislocations with vibration [11]. Combination method of strain-rate cycling tests and the Blaha effect measurement is different from them and would be possible to overcome it. The Blaha effect is the phenomenon that static flow stress decreases when an ultrasonic oscillatory stress is superimposed during plastic deformation [12]. We carry out the strain-rate cycling tests under superimposition of ultrasonic oscillatory stress for $\mathrm{NaCl}$ single crystals doped with $\mathrm{I}^{-}$ions and investigate the interaction between dislocation and the dopant ions in this study. Monovalent ion is considered to have isotropic strain in alkali halide crystal because its size is different from the substituted anion of the host crystal. Its force-distance profile is expressed by Cottrell and Bilby [13].

The dependence of the effective stress and strain-rate sensitivity due to impurities on temperature reveals the force-distance profile between a dislocation and an impurity. The relation between stress and activation volume is also alike. We report the interaction energy between dislocation and the dopant ion in the alkali halide crystals from the mentioned relations given by the measurement of the stress decrement due to application of ultrasonic oscillatory stress and strain-rate sensitivity of flow stress under superimposition of ultrasonic oscillation.

\section{Experimental Procedure}

A schematic illustration of an apparatus is shown in Figure 1. The specimens are $\mathrm{NaCl}$ and $\mathrm{NaCl}: \mathrm{I}^{-}(0.5 \mathrm{~mol} \%$ in the melt) single crystals, which were prepared by cleaving out of single crystalline ingots to the size of $5 \times 5$ $\times 15 \mathrm{~mm}^{3}$. The cleaved specimens were kept immediately below the melting point for $24 \mathrm{~h}$ and were cooled to room temperature at a rate of $40 \mathrm{~K} \cdot \mathrm{h}^{-1}$ in order to reduce dislocation density as much as possible. The preparation method of specimens is the same as described in the previous paper for $\mathrm{NaCl}: \mathrm{Br}^{-}$single crystals [14].

The specimens were lightly fixed on a piezoelectric transducer and were compressed along the $<100>$ axis at $77 \mathrm{~K}$ to room temperature by an INSTRON Type 4465 machine. The upper and bottom sides of specimens were coated with molybdenum disulfide as a lubricant to prevent from barrel shape deformation during the test. A resonator composed of a vibrator and a horn was attached to the testing machine. An ultrasonic oscillatory stress with the signal of $20 \mathrm{kHz}$ from a multifunction synthesizer was intermittently superimposed for one or two minutes in the same direction as the compression. The amplitude of the oscillatory stress was evaluated by the

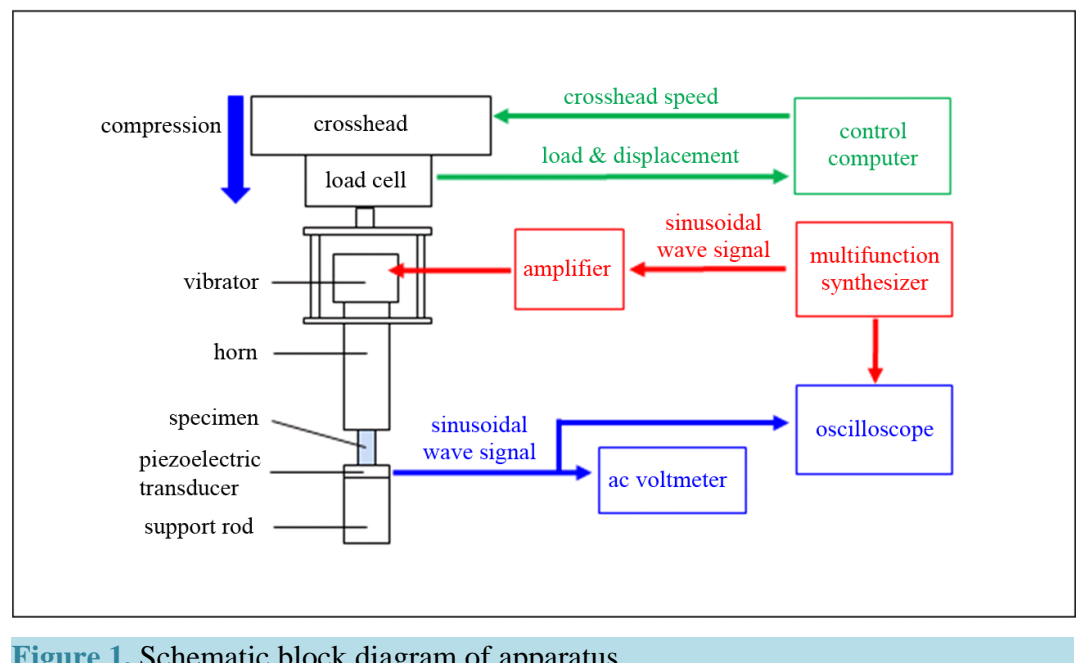

Figure 1. Schematic block diagram of apparatus. 
output voltage from the piezoelectric transducer set between the specimen and a support rod, which was observed by an a.c. voltmeter or an oscilloscope. The strain of specimens seems to be homogeneous because the wave length, which is $225 \mathrm{~mm}$, is 15 times as long as the length of specimens. Strain-rate cycling test associated with the ultrasonic oscillation is illustrated in Figure 2. Application of ultrasonic oscillatory stress during plastic deformation causes a stress drop $(\Delta \tau)$. When strain-rate cycling between the strain-rates of $\dot{\varepsilon}_{1}$ and $\dot{\varepsilon}_{2}$ (i.e. the crosshead speeds of 10 and $50 \mu \mathrm{m} \cdot \mathrm{min}^{-1}$ ) was carried out keeping the stress amplitude, $\tau_{v}$, constant, the stress change due to the strain-rate cycling is $\Delta \tau^{\prime}$. The $\Delta \tau^{\prime} / \Delta \ln \dot{\varepsilon}$ was used as a measure of the strain-rate sensitivity $(\lambda)$ of the flow stress.

\section{Results and Discussion}

\subsection{Relation between $\Delta \tau$ and Strain-Rate Sensitivity $(\lambda)$}

The values of $\Delta \tau$ and $\lambda$ depend on shear strain. The variation of $\Delta \tau$ with the shear strain, $\varepsilon$, is shown in Figure 3(a) for $\mathrm{NaCl}: \mathrm{I}^{-}(0.5 \mathrm{~mol} \%)$ single crystal at $133 \mathrm{~K}$. Figure 3(b) concerns $\lambda$ for the same specimen. The numbers besides each symbol represent the output voltage from the piezoelectric transducer on the support rod, which is proportional to the stress amplitude. $\Delta \tau$ increases with stress amplitude at a given temperature and shear strain. $\lambda$ decreases with increasing stress amplitude and the variation of it with $\tau_{v}$ tends to be small at low and high amplitude at a given strain. $\lambda$ becomes large with strain at all stress amplitude as can be seen in the figure. This is because the forest dislocation density increases with strain. The relations between $\Delta \tau$ and $\lambda$ at each strain of $14 \%$ to $20 \%$ in Figure 3(a) and Figure 3(b) are plotted in Figure 4. The variation of $\lambda$ with $\Delta \tau$ is stair-like. That is to say, the first plateau region ranges below the first bending point at low stress decrement and second one extends from the second bending point at high stress decrement. $\lambda$ decreases gradually with increasing $\Delta \tau$ between the two bending points. Figure 5 corresponds to the case of nominally pure $\mathrm{NaCl}$ single crystals at 97 and $193 \mathrm{~K}$. As for $\mathrm{NaCl}$, the first plateau region does not appear on each curve and $\lambda$ decreases with increasing $\Delta \tau$ at low stress decrement. Figure 6 shows the influence of temperature on the relationship between $\lambda$ and $\Delta \tau$ for $\mathrm{NaCl}: \mathrm{I}^{-}(0.5 \mathrm{~mol} \%)$ single crystals. Similar result as Figure 4 is also obtained at low temperature. The length of $\Delta \tau$ within the first plateau region is referred to as $\tau_{p}$ in the Figure 6 . Therefore, $\tau_{p}$ depends on the dopant ions $\mathrm{I}^{-} . \tau_{p}$ tends to be lower at higher temperature and disappear at room temperature. So far, $\tau_{p}$ has been explained as the effective stress due to the weak obstacles such as the dopant ions which lie on the dislocation when a dislocation begins to break-away from the weak obstacles with the help of thermal activation during plastic deformation of $\mathrm{NaCl}$ single crystals contained three different concentrations of $\mathrm{Br}^{-}$ions $(0.1,0.5$ and 1.0 mol\% in the melt $)$ [14] and $\mathrm{KCl}$ single crystals doped with $\mathrm{Li}^{+}(0.5 \mathrm{~mol} \%$ in the melt $)$ or $\mathrm{Na}^{+}(0.5 \mathrm{~mol} \%$ in the melt) [15]. The weak obstacles are supposed to be $\mathrm{I}^{-}$ions here. It is considered that $\tau_{p}$ is due to $\mathrm{I}^{-}$ions and corresponds to the effective stress due to the ions in this study. Then, $\tau_{p}$ is expected to decrease with increasing temperature. This is shown in Figure 6.

The relative curves of $\Delta \tau$ and $\lambda$ for the two kinds of specimens ( $\mathrm{NaCl}$ and $\left.\mathrm{NaCl}: \mathrm{I}^{-}\right)$shift upward as the strain increases at a given temperature in Figure 4 and Figure 5. This is caused by the part of $\lambda$ which depends on dislocation cuttings.

\subsection{Activation Energy for Breakaway from $I^{-}$Ion by Dislocation}

When the dislocation overcomes $\mathrm{I}^{-}$ions with the aid of thermal activation, $\tau_{p}$ depends on temperature $(T)$. The result is shown in Figure 7 for $\mathrm{NaCl}: \mathrm{I}^{-}$. The value of $\tau_{p}$ decreases with increasing temperature and appears to

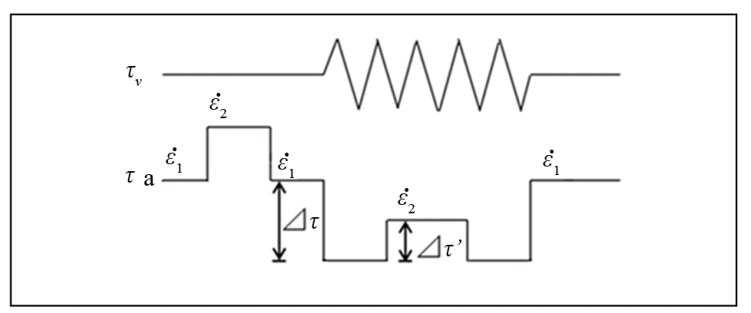

Figure 2. Variation of applied shear stress, $\tau_{a}$, when the strain-rate cycling between the strain rates, $\dot{\varepsilon}_{1}\left(1.1 \times 10^{-5} \mathrm{~s}^{-1}\right)$ and $\dot{\varepsilon}_{2}\left(5.5 \times 10^{-5} \mathrm{~s}^{-1}\right)$, is carried out under superposition of ultrasonic oscillatory shear stress, $\tau_{v}$. 


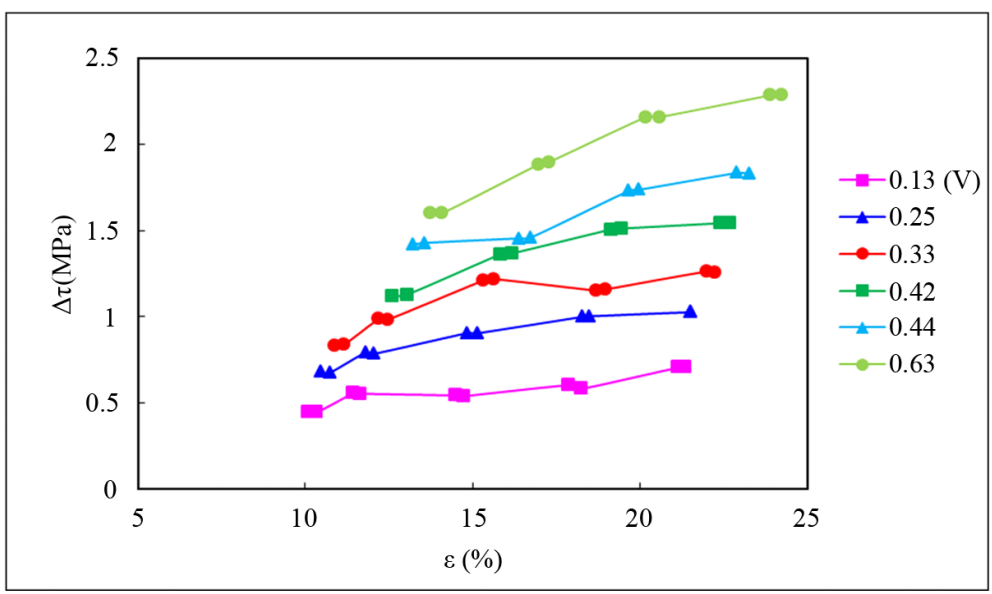

(a)

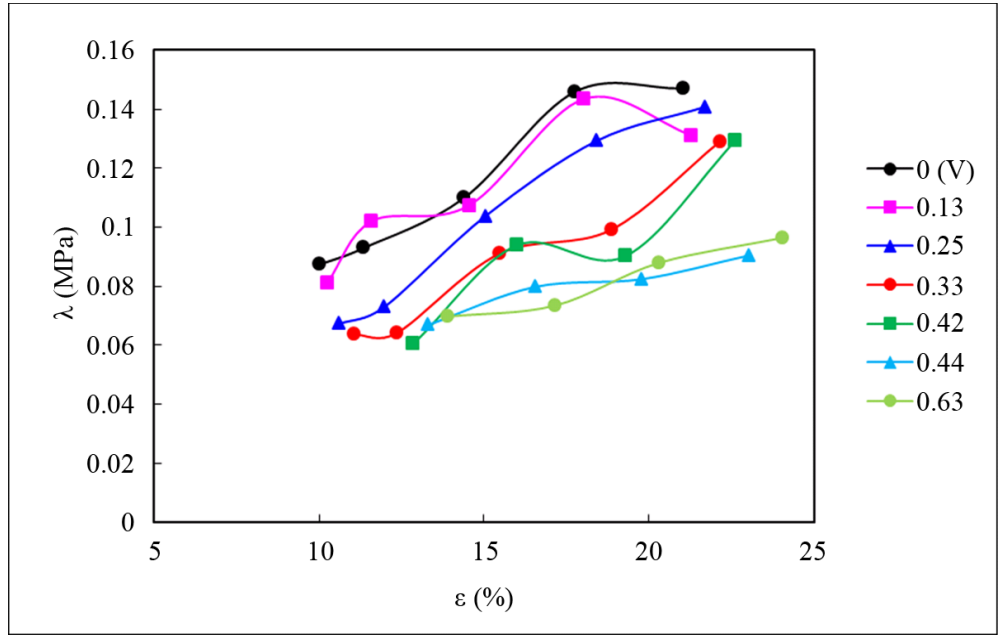

(b)

Figure 3. Dependence of (a) the stress decrement $(\Delta \tau)$ due to superimposition of ultrasonic oscillation and (b) the strain-rate sensitivity $(\lambda)$ of flow stress on the strain $\varepsilon$ at various stress amplitudes and $133 \mathrm{~K}$ for $\mathrm{NaCl}: \mathrm{I}^{-}(0.5 \mathrm{~mol} \%)$.

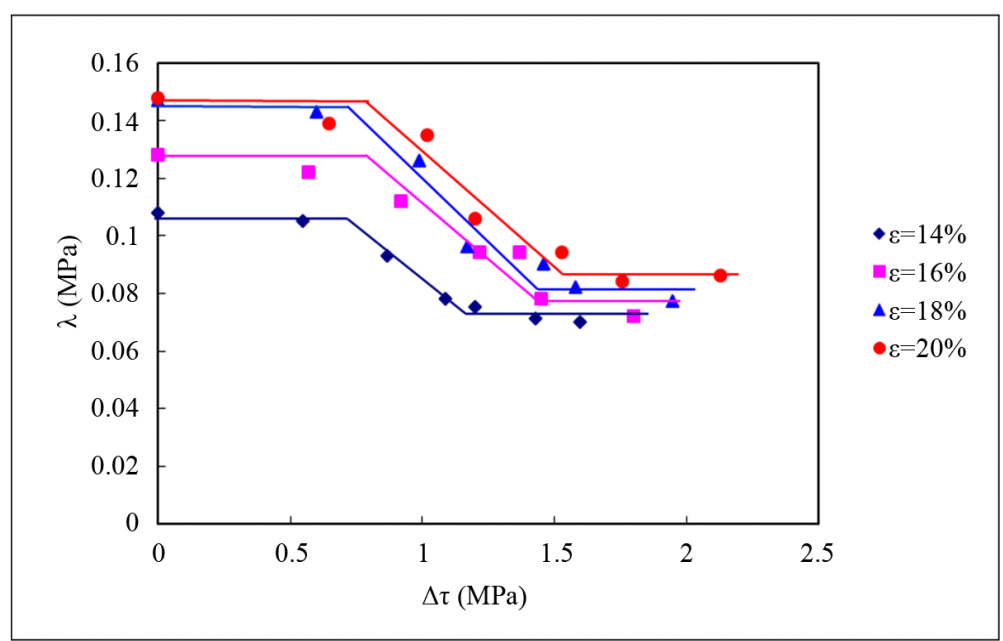

Figure 4. Relation between the $\lambda$ and the stress decrement $(\Delta \tau)$ for $\mathrm{NaCl}: \mathrm{I}^{-}(0.5$ mol\%) at $133 \mathrm{~K}$ and various strains $\varepsilon$. 


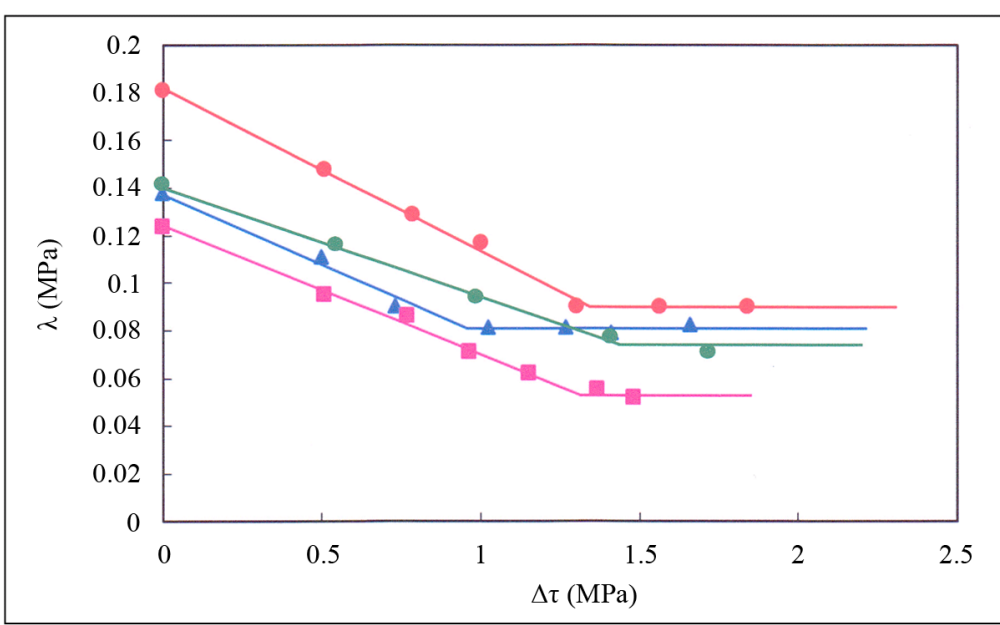

Figure 5. Relation between the $\lambda$ and the stress decrement $(\Delta \tau)$ for $\mathrm{NaCl}$ at various conditions: $(\square) 193 \mathrm{~K}$ and $\varepsilon=9 \%,(\Delta) 193 \mathrm{~K}$ and $\varepsilon=14 \%$, (•) $193 \mathrm{~K}$ and $\varepsilon=19 \%$, ( $) 97 \mathrm{~K}$ and $\varepsilon=3 \%$.

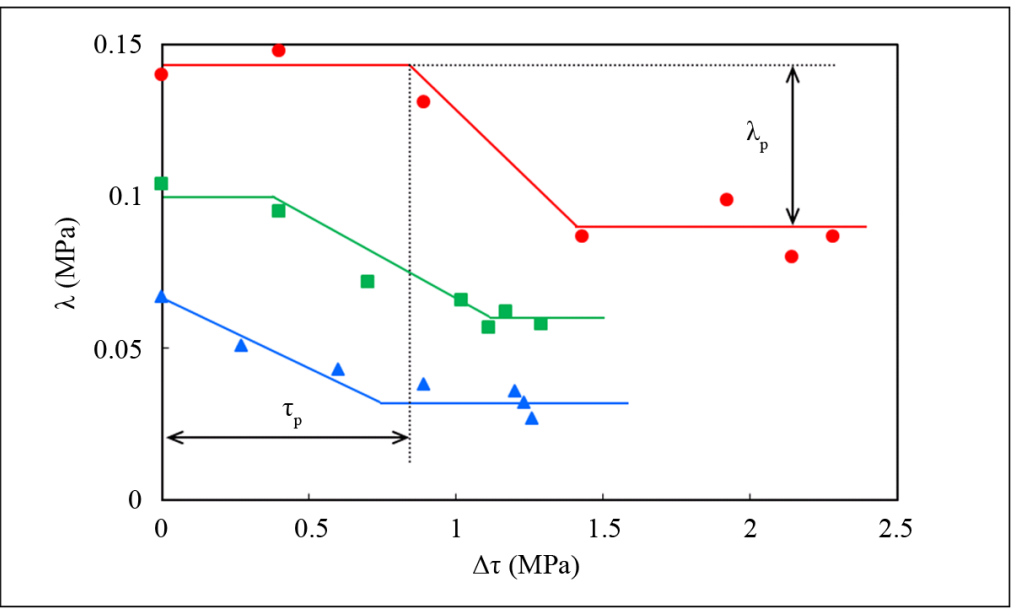

Figure 6. Relation between the $\lambda$ and the stress decrement $(\Delta \tau)$ for $\mathrm{NaCl}: \mathrm{I}^{-}(0.5$ mol\%) at various temperatures: (๑) $77 \mathrm{~K}$ and $\varepsilon=8 \%$, ( $\square) 163 \mathrm{~K}$ and $\varepsilon=12 \%$, (ム) $294 \mathrm{~K}$ and $\varepsilon=10 \%$. $\tau_{p}$ is independent of strain.

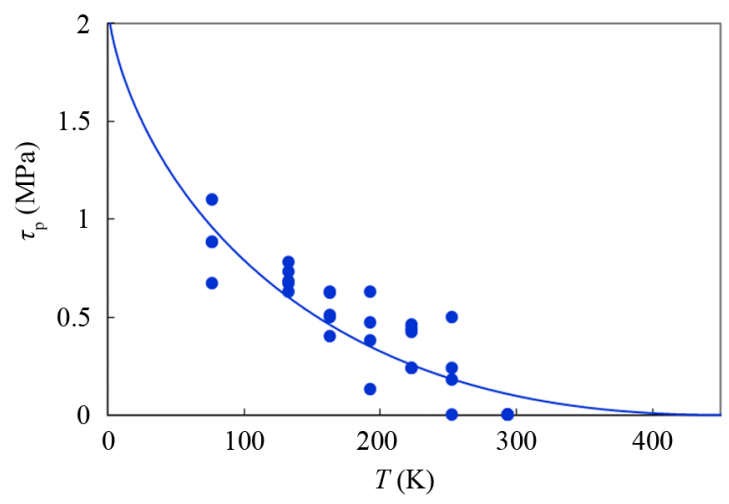

Figure 7. Relation between $\tau_{p}$ and temperature for $\mathrm{NaCl}: \mathrm{I}^{-}(0.5 \mathrm{~mol} \%)$. The solid curve is given by numerical calculation. 
approach to zero at the critical temperature $\left(T_{\mathrm{c}}\right)$ above $400 \mathrm{~K}$. While, $\tau_{p}$ at absolute zero, $\tau_{p 0}$, seems to be around $2 \mathrm{MPa}$.

The difference between $\lambda$ at first plateau place and at second one, $\lambda_{p}$ defined in Figure 6, has been regarded as a component of strain-rate sensitivity due to dopant ions [16] [17]. $\lambda_{p}$ is proportional to the inverse of the average spacing, $l_{p}$, of dopant ions on a dislocation as given by

$$
\lambda_{p}=k T / b l_{p} d
$$

where $k$ is the Boltzmann constant, $b$ the magnitude of Burgers vector, and $d$ the activation distance. Figure 8 shows the dependence of $\lambda_{p}$ on temperature. The solid circles correspond to the $\lambda_{p}$ for the specimen. Figure 7 and Figure 8 reflect the interaction between dislocation and $\mathrm{I}^{-}$ion. Assuming that the force-distance relation between a dislocation and $\mathrm{I}^{-}$can be approximated to the Cottrel-Bilby relation [13] taking account of the Friedel relation [18], the dependence of $\tau_{p}$ and $\lambda_{p}$ on temperature is revealed as the solid curves in these figures. The determination of $T$ vs. $\tau_{p}$ and $T$ vs. $\lambda_{p}$ curves is calculated by using parameters of $\tau_{p 0}, T_{\mathrm{c}}$ and $G_{0} . G_{0}$ is the Gibbs free energy for overcoming of the isotropic strain around $\mathrm{I}^{-}$ion by dislocation at absolute zero. These curves are agreed with the experimental data (i.e. solid circles) analyzed in terms of $\lambda$ versus $\Delta \tau$ for the specimens, although the data is slightly scattered.

Figure 9 shows the relation between $\tau_{p}$ and activation volume $(V)$ for $\mathrm{NaCl}: \mathrm{I}^{-}$, where $V$ is given by $k T / \lambda_{p}$. This figure also represents the interaction between dislocation and $\mathrm{I}^{-}$ion. And solid curve is determined on the basis of the above-mentioned model and by using the least squares method. Then, the parameters $\left(\tau_{p 0}, T_{\mathrm{c}}\right.$ and $\left.G_{0}\right)$ used are denoted in Table 1. Furthermore, those for $\mathrm{NaCl}$ single crystals contained $\mathrm{Br}^{-}$ions $(0.5 \mathrm{~mol} \%$ in the melt) are also listed in the table, where the parameters for $\mathrm{NaCl}: \mathrm{Br}^{-}$are estimated again by similar method as $\mathrm{NaCl}: \mathrm{I}^{-}$ in accordance with $\lambda$ versus $\Delta \tau$ curves reported in the previous paper [14]. The value of $G_{0}$ for $\mathrm{NaCl}: \mathrm{I}^{-}$is somewhat larger than for $\mathrm{NaCl}: \mathrm{Br}^{-}$. This suggests that $\mathrm{I}^{-}$ion are slightly stronger than $\mathrm{Br}^{-}$one as weak obstacle to dislocation motion, because the isotropic strain around $\mathrm{I}^{-}$ion is large in comparison with that around $\mathrm{Br}^{-}$in $\mathrm{NaCl}$ single crystal.

\section{Conclusions}

The relative curves of $\lambda$ and $\Delta \tau$ due to application of ultrasonic oscillatory stress have stair-like shape for $\mathrm{NaCl}$ single crystals doped with $\mathrm{I}^{-}$at low temperatures. There are two bending points and two plateau regions. $\lambda$ decreases

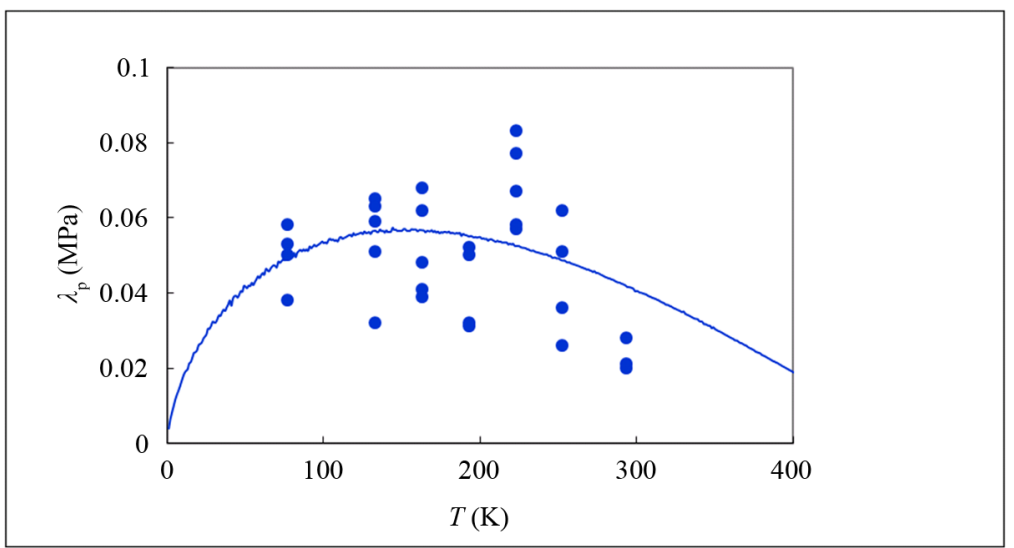

Figure 8. Dependence of $\lambda_{p}$ on temperature for $\mathrm{NaCl}: \mathrm{I}^{-}$(0.5 mol\%). The solid curve is given by numerical calculation.

Table 1. Parameters used for calculation (Interaction between dislocation and $\mathrm{Br}^{-}$or $\mathrm{I}^{-}$is approximated to the Cottrel-Bilby relation taking account of the Friedel relation).

\begin{tabular}{cccc}
\hline Specimen & $G_{0}(\mathrm{eV})$ & $\tau_{\mathrm{p} 0}(\mathrm{MPa})$ & $T_{\mathrm{c}}(\mathrm{K})$ \\
\hline $\mathrm{NaCl}: \mathrm{Br}^{-}(0.5 \mathrm{~mol} \%)$ & 0.47 & 2.85 & 363.30 \\
$\mathrm{NaCl}: \mathrm{I}^{-}(0.5 \mathrm{~mol} \%)$ & 0.53 & 2.07 & 465.54 \\
\hline
\end{tabular}




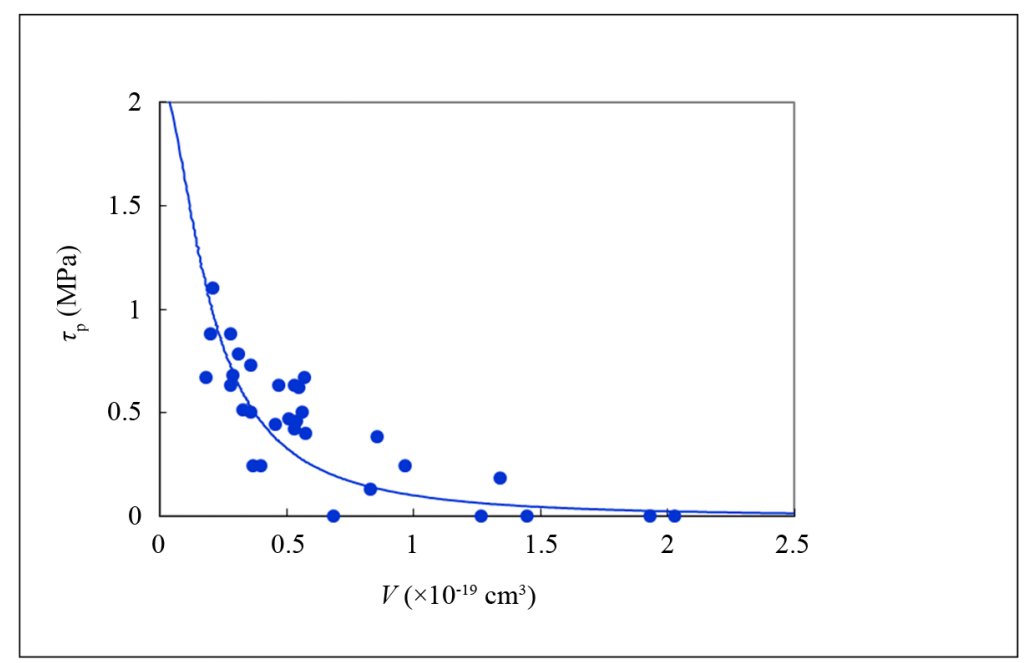

Figure 9. Relation between $\tau_{p}$ and activation volume for $\mathrm{NaCl}: \mathrm{I}^{-}(0.5 \mathrm{~mol} \%)$.

The solid curve is given by numerical calculation.

with $\Delta \tau$ between the two bending points.

$\tau_{p}$ and $\lambda_{p}$ depend on the dopant ions as weak obstacles to dislocation motion. Not only temperature dependence of $\tau_{p}$ and $\lambda_{p}$ but also $\tau_{p}$ versus $V$ reflects the interaction between dislocation and $\mathrm{I}^{-}$ions. On the basis of the data analyzed in terms of the relative curves of $\lambda$ and $\Delta \tau$, the activation energy for the overcoming of dislocation from the dopant ion is found to be 0.47 and $0.53 \mathrm{eV}$ for $\mathrm{NaCl}: \mathrm{Br}^{-}$and $\mathrm{NaCl}: \mathrm{I}^{-}$, respectively. This result that $G_{0}$ for $\mathrm{NaCl}: \mathrm{I}^{-}$is somewhat larger than for $\mathrm{NaCl}: \mathrm{Br}^{-}$leads to the phenomenon that $\mathrm{I}^{-}$ion is slightly stronger than $\mathrm{Br}^{-}$one as weak obstacle to dislocation motion because of the difference between isotropic strains around $\mathrm{I}^{-}$ion and around $\mathrm{Br}^{-}$in $\mathrm{NaCl}$ single crystal.

\section{Acknowledgements}

We would like to thank E. Ogawa for his experimental assistance.

\section{References}

[1] Susyñska, M. (1974) Effect of Impurity Concentration and Plastic Deformation on Dislocation Density of KCl Crystals. Kristall und Technik, 9, 1199-1207. http://dx.doi.org/10.1002/crat.19740091015

[2] Kataoka, T. and Yamada, T. (1977) Yield Strength and Dislocation Mobility of KCl-KBr Solid Solution Single Crystals. Japanese Journal of Applied Physics, 16, 1119-1126. http://dx.doi.org/10.1143/JJAP.16.1119

[3] Okazaki, K. (1996) Solid-Solution Hardening and Softening in Binary Iron Alloys. Journal of Materials Science, 31, 1087-1099. http://dx.doi.org/10.1007/BF00352911

[4] Tabachnikova, E.D., Podolskiy, A.V., Smirnov, S.N., Psaruk, I.A. and Liao, P.K. (2014) Temperature Dependent Mechanical Properties and Thermal Activation Plasticity of Nanocrystalline and Coarse Grained Ni-18.75 at.\% Fe Alloy. IOP Conference Series: Materials Science and Engineering, 63, 012105. http://dx.doi.org/10.1088/1757-899X/63/1/012105

[5] Messerschmidt, U., Appel, F. and Schmid, H. (1985) The Radius of Curvature of Dislocation Segments in MgO Crystals Stressed in the High-Voltage Electron Microscope. Philosophical Magazine, 51, 781-796. http://dx.doi.org/10.1080/01418618508237587

[6] Kataoka, T., Ohji, H., Kishida, K., Azuma, K. and Yamada, T. (1990) Direct Observation of Glide Dislocations in a KCl Crystal by the Light Scattering Method. Applied Physics Letters, 56, 1317-1319. http://dx.doi.org/10.1063/1.102504

[7] Ivanov, V.I., Lebedev, A.B., Kardashev, B.K. and Nikanorov, S.P. (1986) Interaction of Dislocations with Pinning Centers in Magnesium at temperatures 295-4.2K. Soviet Physics-Solid State, 28, 867-868.

[8] Kosugi, T. and Kino, T. (1987) Experimental Determination of the Force-Distance Relation for the Interaction between a Dislocation and a Solute Atom. Journal of the Physical Society of Japan, 56, 999-1009. http://dx.doi.org/10.1143/JPSJ.56.999 
[9] Kosugi, T. (2001) Temperature Dependence of Amplitude-Dependent Internal Friction Due to Simultaneous Breakaway of a Dislocation from Several Pinning Points. Materials Science and Engineering: A, 309-310, 203-206. http://dx.doi.org/10.1016/S0921-5093(00)01792-5

[10] Johnston, W.G. and Gilman, J.J. (1959) Dislocation Velocities, Dislocation Densities, and Plastic Flow in Lithium Fluoride Crystals. Journal of Applied Physics, 30, 129-144. http://dx.doi.org/10.1063/1.1735121

[11] Granato, A.V. and Lücke, K. (1956) Theory of Mechanical Damping Due to Dislocations. Journal of Applied Physics, 27, 583-593. http://dx.doi.org/10.1063/1.1722436

[12] Blaha, F. and Langenecker, B. (1955) Dehnung von Zink-Kristallen unter Ultraschalleinwirkung. Naturwissenschaften, 42, 556. http://dx.doi.org/10.1007/BF00623773

[13] Cottrell, A.H. and Bilby, B.A. (1949) Dislocation Theory of Yielding and Strain Ageing of Iron. Proceedings of the Physical Society of London, A62, 49-62. http://dx.doi.org/10.1088/0370-1298/62/1/308

[14] Ohgaku, T. and Teraji, H. (2001) Investigation of Interaction between a Dislocation and a $\mathrm{Br}^{-}$Ion in $\mathrm{NaCl}^{-\mathrm{Br}^{-}} \mathrm{Single}$ Crystals. Physica Status Solidi (a), 187, 407-413. http://dx.doi.org/10.1002/1521-396X(200110)187:2<407::AID-PSSA407>3.0.CO;2-Q

[15] Kohzuki, Y. (2010) Bending Angle of Dislocation Pinned by an Obstacle and the Friedel Relation. Philosophical Magazine, 90, 2273-2287. http://dx.doi.org/10.1080/14786431003636089

[16] Kohzuki, Y., Ohgaku, T. and Takeuchi, N. (1995) Interaction between a Dislocation and Various Divalent Impurities in KCl Single Crystals. Journal of Materials Science, 30, 101-104. http://dx.doi.org/10.1007/BF00352137

[17] Ohgaku, T. and Matsunaga, T. (2009) Interaction between Dislocation and Divalent Impurity in KBr Single Crystals. IOP Conference Series: Materials Science and Engineering, 3, 012021. http://dx.doi.org/10.1088/1757-899X/3/1/012021

[18] Friedel, J. (1964) Dislocations. Pergamon Press, Oxford, 223-226. 